\title{
Scintillation Counter Method of Intercomparing Neutron Source Strengths by Means of a Manganous Sulfate Bath
}

\author{
Earl R. Mosburg, Jr.
}

\begin{abstract}
It has proved feasible to use a scintillation counter to measure the relative activity of a large manganous sulfate bath, thereby determining the neutron-emission rates of neutron sources relative to the national standard neutron source of the National Bureau of Standards. A scintillation counter allows the calibration of sources weaker by a factor of seven than those it was previously possible to calibrate by means of a Geiger-Muller counter. The use of $\mathrm{Cs}^{137}$ as a reference pulse height to which the scintillation counter system is adjusted by means of a two channel pulse height analyzer makes possible the reliable reproduction of results from day to day. By using the scintillation counter the ratio of the national reference standard neutron source (NBS-II) to the national standard neutron source (NBS-I) has been redetermined and is found to be $0.939_{3} \pm 0.001_{7}$.
\end{abstract}

\section{Introduction}

The routine determination of neutron-emission rates of "radioactive" neutron sources in terms of the emission rate of the NBS Ra-Be $(\gamma, n)$ national standard source, known as NBS-I, has for sometime been carried out by means of a manganous sulfate bath. In this method, which was also used to calibrate the national neutron standard absolutely, ${ }^{1}$ the source is suspended for approximately $18 \mathrm{hr}$ in the center of a cylindrical bath of manganous sulfate solution of $1-\mathrm{m}$ depth and $1-\mathrm{m}$ diam. The fast neutrons are moderated in the water and an appreciable and constant fraction of them are then captured by the manganese. Integration of the $\mathrm{Mn}^{56}$ activity over all radii is accomplished by thoroughly mixing the solution before the count is started. Counting of the $\mathrm{Mn}^{56}$ activity has normally been accomplished by the use of a Geiger-Muller counter suspended in the center of the bath. This paper will describe the use of a scintillation counter placed in the center of the bath and the means used to obtain the high degree of pulse-height reproducibility and stability that is required.

When the bath is activated to near saturation by NBS-I (neutron yield $Q=1.26 \times 10^{6}$ neutrons $/ \mathrm{sec}$ ) and counted with a Geiger counter, ${ }^{2}$ the integrated count over approximately a half life of $\mathrm{Mn}^{56}(2.58$ $\mathrm{hr}$ ) is 31,300 counts, of which 12 percent are due to background radiation. Assuming an equal counting time in determining the background, the statistical error $(\sqrt{n})$, in the value of the bath activity is then close to 0.7 percent. Background levels show slight changes over periods of days which further add to this uncertainty. If a calibration of a weaker source is desired, the accuracy quickly worsens. For example, if the neutron yield of the source is $10^{5}$ neutrons/sec the background amounts to 62 percent of the total count and the statistical error in the value of the bath activity is 4.4 percent.

1 James DeJuren and Jack Chin, J. Research NBS 55, 311 (1955) RP2635.
To obtain ratios of the neutron yields of two sources to accuracies of 0.5 percent, some improvement in the calibration procedure is indicated. An increase in counting time is of no avail since we already have half of the total time integrated count obtainable with the Geiger counter system.

\section{Scintillation Counter Method}

A much higher efficiency is achieved if, instead of a Geiger counter, a $\mathrm{NaI}(\mathrm{Tl})$ scintillator is used for dip counting of the activated manganese. However, a scintillation counter produces a continuous pulse height distribution with a general increase in the number of pulses at lower pulse heights until the distribution blends into the noise spectrum of the photomultiplier tube. Thus some discrimination level must be set and pulses of height lower than this limit rejected. This discrimination level must be capable of accurate repetition from day to day and must possess considerable time stability. The overall gain stability of the system must be appreciably better than one percent. In addition it must be possible to determine the position of the discrimination level by a means which will give accuracies of better than 1 percent within a short period of time.

The use of the sharp $662 \mathrm{Kev} \gamma$-line of $\mathrm{Cs}^{137}$ offers a quick and accurate pulse height reference. As is shown in the block diagram (fig. 1) the $\mathrm{Cs}^{137}$ pulses from the probe, after amplification in a linear amplifier, are fed to a two-channel differential pulse height analyzer consisting of a triple discriminator of high stability followed by a dual-channel anticoincidence circuit. The spacing between the levels of the triple discriminator is fixed at about half of the width of the cesium peak. The calibration of the pulse height is then made by adjusting the gain of the amplifier for equal counting rates in the two pulse-height channels when the cesium source is near the probe. In

2 N. Wood Counter Laboratory, Chicago, Ill., 41/2 in, active length, 1 in diameter. 


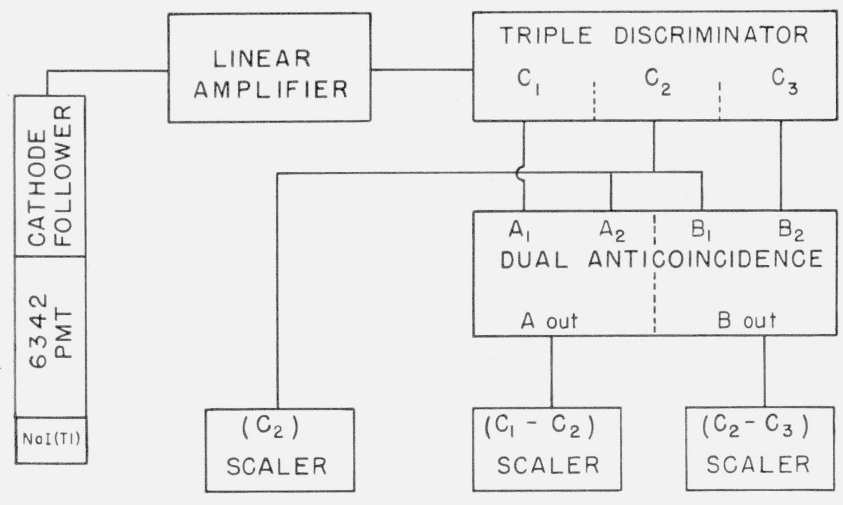

Figure 1. Block diagram of electronic circuitry.

figure 2 are shown the pulse-height distributions obtained from $\mathrm{Cs}^{137}$ and $\mathrm{Mn}^{56}$ as well as the positions of the triple discriminator levels, $C_{1}, C_{2}$, and $C_{3}$. After the pulse-height adjustment with the cesium, the cesium source is removed and the bath activity is determined by counting the output $C_{2}$ of the triple discriminator which is then centered on the cesium peak. Considering small variations in amplification, it is clear that a relatively small percentage change in the count rate of discriminator $C_{2}$ for a cesium source is associated with a much smaller percentage change for a $\mathrm{Mn}^{56}$ source. The ratio is in fact about 16. The statistical error in the count rate difference between the two pulse height channels for a 1-min count with the cesium source in the standard position permits an accuracy in the adjustment of pulse height which corresponds to an error of only 0.04 percent in the $\mathrm{Mn}^{56}$ count rate. There are still present, however, short term variations in the overall gain which cause the difference in the count rates of the two channels to vary, during a period of an hour or less, by an amount greater than the statistical error associated with a 1 -min cesium count. These variations, which correspond to pulse height variations of less than 0.4 percent, are associated with less than a 3.5-percent error in the cesium count rate or less than a 0.2 -percent error in the $\mathrm{Mn}^{56}$ count rate.

The use of a $1 \frac{1}{2} \times 1 \frac{1}{2}$ in. $\mathrm{NaI}(\mathrm{Tl})$ scintillation counter in determining bath activity provides counting rates which are higher by a factor of 9 than those of the Geiger counter previously used. Moreover, the fact that the percentage of pulses which are of pulse height above the discrimination level is lower for the background than for $\mathrm{Mn}^{56}$, results in a reduction in the ratio of background to total count from 12 percent to 3 percent when the bath is activated by NBS-I. Thus sources of lower total neutron yield may now be calibrated in the bath. Table 1 compares the statistical errors in the determination of bath activity for sources of various neutron yields by both the Geiger and scintillation counter methods. If the statistical error in the determination of the bath activity is required to be less than 1.0 percent the use of the scintillation counter allows the calibration of a source smaller in yield by a factor of more

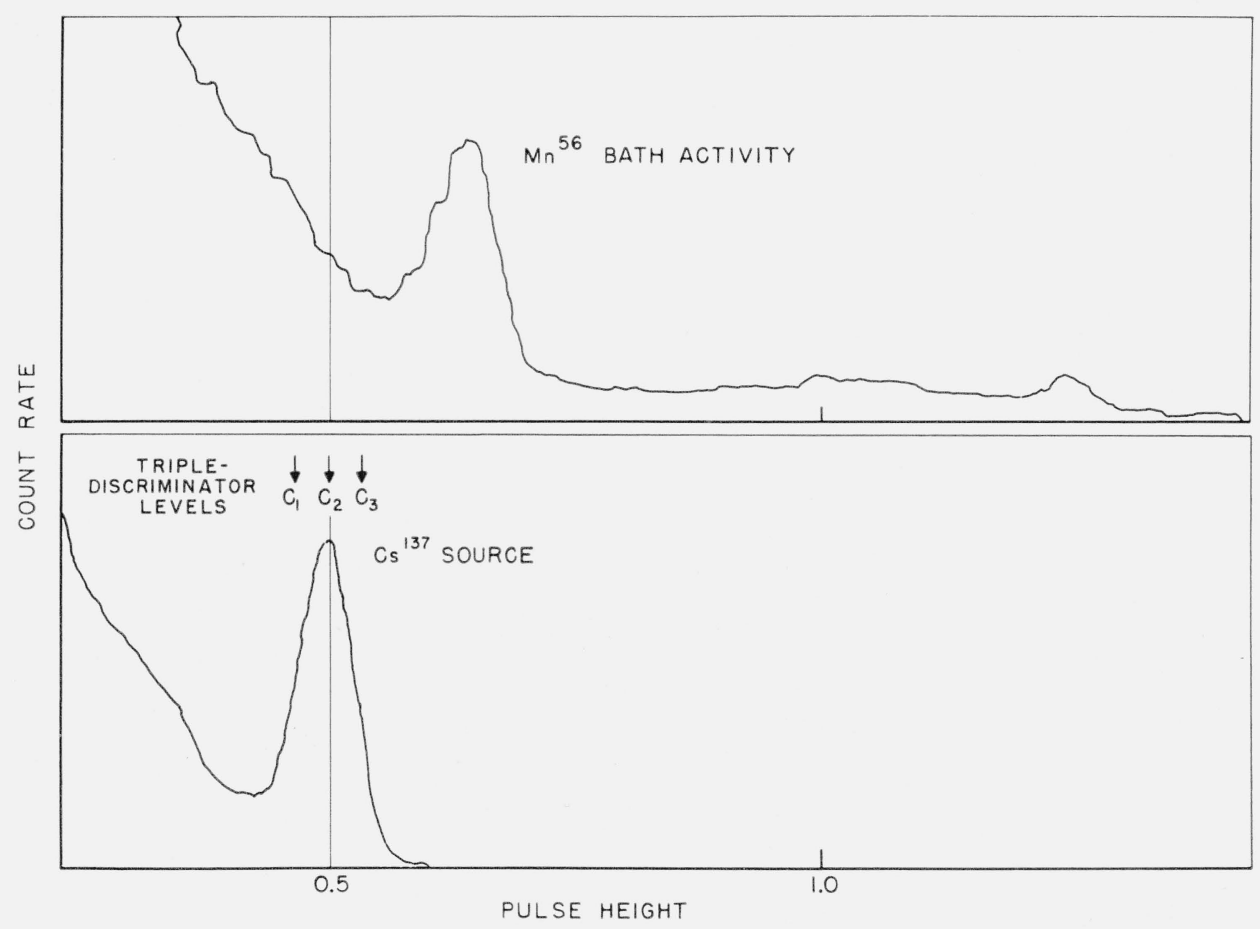

FIGURE 2. Pulse height distributions from gamma rays from $\mathrm{Mn}^{56}$ in manganous sulfate bath and from $\mathrm{Cs}^{137}$ source. 
TABLE 1. Calculated values associated with the measurement of the manganous sulfate bath activity

\begin{tabular}{|c|c|c|c|c|c|c|}
\hline \multirow[b]{2}{*}{$\begin{array}{l}\text { Neutron emission } \\
\text { rate of the source }\end{array}$} & \multicolumn{2}{|c|}{$\begin{array}{l}\text { Geiger counter } \\
155-\text { min count }\end{array}$} & \multicolumn{2}{|c|}{$\begin{array}{l}\text { Scintillation } \\
\text { counter 155-min } \\
\text { count }\end{array}$} & \multicolumn{2}{|c|}{$\begin{array}{l}\text { Scintillation } \\
\text { counter } 15 \text {-min } \\
\text { count }\end{array}$} \\
\hline & $\begin{array}{l}\text { Ratio of } \\
\text { back- } \\
\text { ground } \\
\text { to total }\end{array}$ & $\begin{array}{l}\text { Stand- } \\
\text { ard de- } \\
\text { viation } \\
\text { in bath } \\
\text { activity }\end{array}$ & $\begin{array}{l}\text { Ratio of } \\
\text { back- } \\
\text { ground } \\
\text { to total }\end{array}$ & $\begin{array}{l}\text { Stand- } \\
\text { ard de- } \\
\text { viation } \\
\text { in bath } \\
\text { activity }\end{array}$ & $\begin{array}{l}\text { Ratio of } \\
\text { back- } \\
\text { ground } \\
\text { to total }\end{array}$ & $\begin{array}{l}\text { Stand- } \\
\text { ard de- } \\
\text { viation } \\
\text { in bath } \\
\text { activitya }\end{array}$ \\
\hline $\begin{array}{c}1.26 \times 10^{6}(\mathrm{NBS}-\mathrm{I}) \\
7 \times 10^{5} \\
3 \times 10^{5} \\
10^{5}\end{array}$ & $\begin{array}{l}0.116 \\
.193 \\
.36 \\
.62\end{array}$ & $\begin{array}{l}\% \\
0.68 \\
.98 \\
1.8 \\
4.4\end{array}$ & $\begin{array}{l}0.029 \\
.111 \\
.273\end{array}$ & $\begin{array}{c}\% \\
0.21 \\
-0.49 \\
0.94\end{array}$ & 0.029 & $\begin{array}{c}\% \\
0.66 \\
-.- \\
--\end{array}$ \\
\hline
\end{tabular}

a In computing the standard deviation, the background count is assumed equal in length to the activated bath count in each case.

than seven or the calibration of a source of yield $1.26 \times 10^{6}$ in less than one-tenth of the time required by the Geiger counter. Of course these values apply only to the specific counter used. Improvements in sensitivity can easily be made by simply using a larger scintillator in the bath.

In order to achieve the needed stability in gain, the scintillator and photomultiplier must be temperature stabilized. The pulse height from such scintillating systems bas a negative temperature coefficient which amounts to as much as 0.5 percent per degree centigrade. ${ }^{3}$ The temperature stabilization is accomplished by immersing the probe in the manganous sulfate bath one-half hour before adjusting the gain on the cesium peak. The heat capacity of the bath is sufficiently large to preclude any appreciable temperature change over the combined time interval required for the gain adjustment with cesium and for the subsequent count of the bath activity.

Another effect which was considered is the variation of pulse height with counting rate. ${ }^{4}$ The change in pulse height with count rate was determined by observing the shift in the balance point with the $\mathrm{Cs}^{137}$ source in a standard position, when a $\mathrm{Ba}^{133}$ source was placed at various distances from the source. The spectrum of the Ba source has a maximum pulse height below the cesium peak and thus

3 W. P. Ball, R. Booth, and M. MacGregor, Nuclear Instruments 1, 71 (1957). 4 P. R. Bell, R. C. Davis, and W. Bernstein, Rev. Sci. Instr. 26, 726 (1955). does not contribute counts in the region of the cesium peak. The absolute count rate in the photomultiplier tube due to the cesium source was estimated using an extrapolation of the cesium pulse height distribution to zero pulse height. The absolute count rates with both cesium and $\mathrm{Ba}^{133}$ present were then estimated by relative measurements with the scintillation counter replaced by a Geiger counter. A variation of count rate by a factor of two from that due to the cesium source alone results in a shift in pulse height of the cesium peak of about 0.25 percent. This would correspond to an error in the manganese bath count of 0.13 percent. Since most of the sources tested are of approximately the same strength this factor is not too important. However this effect will be investigated more thoroughly.

\section{Redetermination of the Ratio of NBS Standard Sources}

The ratio of the emission rate $(Q)$ of the National Bureau of Standards national reference standard neutron source NBS-II to that of the national neutron standard NBS-I was redetermined using the scintillation dipcounter in a series of measurements involving five irradiations of the bath by NBS-I and four by NBS-II. The best value for the ratio, based on 21 counts of the NBS-I bath activity and 16 counts of the NBS-II bath activity, is:

$$
\frac{Q(\mathrm{NBS}-\mathrm{II})}{Q(\mathrm{NBS}-\mathrm{I})}=0.939_{3} \pm 0.001_{7}
$$

where the error given is the standard deviation, which is about 30 percent higher than the error expected on the basis of $\sqrt{n}$ alone. The distributions of deviations from the weighted average values of the bath activities are normal and the largest deviation for a single measurement is about $3 \frac{1}{2}$ standard deviations.

The author thanks Louis Costrell for the design of some of the circuits and William Murphy and Jack Chin for assistance in taking the data.

Washington, December 29, 1958. 